\title{
Developing an Innovative Web-Based Application for Clusterization in Healthcare - SANINFO
}

Viorica BADEA ${ }^{1}$, Carmen RUSU², Marius GERU ${ }^{3}$ Cosmin STAMATE ${ }^{4}$

\begin{abstract}
The Health Information System is widely used in healthcare contexts and has improved the performance, state, and effectiveness of health services and the overall patient well-being. Following the reform of the Romanian health system, and the context created by the COVID-19 context, there is an increased demand for such platforms. In order to strengthen the Primary Health Care system, there is a need to design new services performed with the assistance of information technologies that can reduce the costs and increase the quality of the health care services. This study provides relevant information about (1) the planning and development of the health information system, (2) the needed hardware architecture, (3) the usability and design standards for health information systems, (4) the testing and validation in the local market, (5) the integration of all requirements resulting from the system testing and (6) the continuous integrations and updates. All the information obtained during the planning stage is based on previous research regarding the analysis of existing national and international online medical systems.
\end{abstract}

Keywords: healthcare, information systems, health information system, health information technology, digital health, medical hub, Covid-19.

\section{Rezumat}

Sistemul de informații privind sănătatea este utilizat pe scară largă în contextele de asistență medicală și a îmbunătățit performanța, starea și eficacitatea serviciilor de sănătate și starea de bine a pacientului. În urma reformei, sistemului de sănătate din România și a contextului creat de virusul COVID-19, există o cerere crescută pentru astfel de platforme. Pentru a consolida sistemul de asistență medicală primară, este necesară proiectarea și implementarea de noi servicii prestate cu ajutorul tehnologiilor informaționale care pot reduce costurile și crește calitatea serviciilor de asistență medicală. Acest studiu oferă informații relevante despre (1) planificarea și dezvoltarea sistemului de informații pentru sănătate, (2) arhitectura hardware necesară, (3) standardele de utilizare și design pentru sistemele de informații de sănătate, (4) testarea și validarea pe piața locala, (5) integrarea tuturor cerințelor rezultate din testarea sistemului și (6) integrarea și actualizarea recurentă. Toate informațiile obținute pe parcursul etapei de planificare se bazează pe cercetări anterioare privind analiza sistemelor medicale din mediul online, naționale și internaționale.

Cuvinte cheie: asistență medicală, sistem de informații, sistem de informații privind sănătatea, tehnologie informațională, sănătate digitalizată, Covid-19.

' Open Hub Creative Cluster, Galati, Romania

2 "Dunarea de Jos" University of Galati, Romania

${ }^{3}$ University of Transylvania, Brasov, Romania

${ }^{4}$ Birkbeck, University of London, Great Britain
Corresponding author.

Viorica BADEA, Open Hub Creative Cluster, Galati, Romania.

E-mail: viorica@achieveseo.com 


\section{INTRODUCTION}

Health Information Systems (HIS) are recognized as an essential means to strengthen Primary Health Care (PHC) in developing countries ${ }^{1}$. Limitations in technical know-how and scarcity of human resources have allowed these technologies to be used only for selected services. The ease of use of such systems and the social context created by COVID-19 allowed an effective intervention in developing the Health Information Systems in Romania serving urban communities in the South-East region of Romania.

The developed health information system will be referred to by the acronym SANINFO and is publicly available at saninfo.ro (launched since 31.10.2019). It demonstrates how technology is used as a tool for dissemination by improving the awareness of the existing know-how in the medical field at any age stage, for different categories of users. The process of design and development of the SANINFO platform provides intuitive support through the advanced web technologies used during the implementation phase.

The SANINFO system matches the population information and prevention needs in the medical field by increasing the visibility of the scientific information resulting from research and innovation activities carried out within the cluster. Within the SANINFO platform, which is based on an open-source implementation, products and services of planned and developed research and development activities focus on the cooperation with cluster members with the scope of promoting and disseminating scientific healthcare information at a national and international level.

The project implemented by the Innovative Cluster for Health „Lower Danube” (www.csdj.ro), financed under the program „Cluster organization and development - Innovative Cluster (CLS)" is entitled Development of an Innovative Health Information System SANINFO. The Innovative Cluster for Health „Lower Danube" (http://clustero.eu/members) started in 2013 based on the need of improving access to healthcare, health education and education competitiveness of its members.

During the development process, there was an integral feedback loop provided by physicians and nurses organized in three focus groups where the developers integrated specific features. Martikainen et al. ${ }^{3}$, emphasizes the use of Participatory methods in HIS development, but at the same time, notes the challenge of limited availability of medical personnel. There is a particularly difficult task in de design and development of products accommodating the exigencies of medical staff and the needs of end-users ${ }^{4}$.

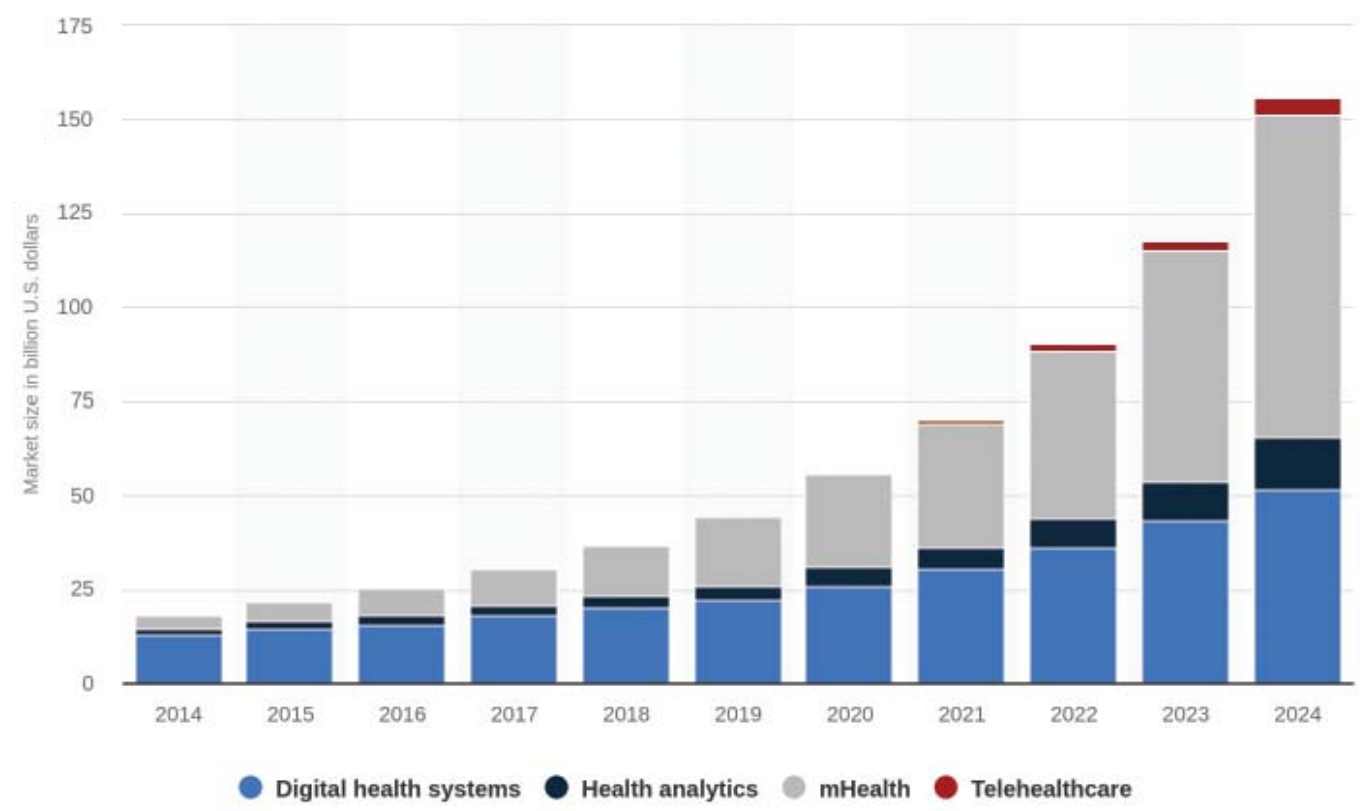

Figure 1. Technology used in Digital health; market size in the United States; source statista.com. 


\section{DIGITAL HEALTH AND HEALTH INFORMATION SYSTEMS}

Digital health describes the applicability of technology and data-driven software applications for monitoring and enhancing patient wellbeing ${ }^{11}$. The importance of information accessibility in medical services is the main aim of the cluster validated through an online Health Information - SANINFO. The cluster brings together 20 members, entities and organizations from different domains of activity: medical (primary medicine, dentistry, social assistance, emergency), educational, engineering and ICT. The diversity of expertise of the cluster members constitutes a favorable framework in supporting and implementing innovative projects in the medical sector, education, and information.

The planning process of the platform's main features started with the study performed on the existing medical platforms, as well as the use of the available resources and current technologies. One of the results of the study is the acute need to provide a holistic medical service that brings together all branches of medicine and perform the following functions: information, prevention, communication, interaction, scheduling, location and recommendation. The existence of the online platform aims to allow and integrate collaborative activities at all levels between cluster members while linking competencies and their availability. All these features are classified under the label digital health systems or Health Information Systems and increasing market worldwide estimating to reach more than 50 billion dollars in us alone in 2025 (Figure 1).

Digital health aims to offer clinical decision support, and it is collected with the increasing market of mHealth (mobile health), considering the ease of collecting data from patients. Aggregating and understanding the collected data, digital health can act as a driver of health strategies.

\section{WORK METHODOLOGY WITHIN THE TECHNICAL TEAM FOR THE DEVELOPMENT OF THE APPLICATION}

The SANINFO project aims to support the increase in competitiveness in the medical field of the members of the Innovative Cluster for Health "Dunărea de Jos", by focusing the available resources on the development of services through an innovative health information system. SANINFO platform intends to provide information support in the medical field at national and in- ternational level. Inadvertently this outcome will result in an increase in the market competitiveness of current companies and research entities within the cluster. The project has reached the following objectives: (1) promoting information and health education (2) developing and promoting new systems and techniques in the medical field to maintain patient health; (3) improving access to the medical market; (4) supporting and promoting a unitary healthcare framework among beneficiaries.

Based on the project specifications, the project team consists of five web experts having the following roles:

1. Project Manager

2. Graphic Designer

3. Back-end programmer

4. Front-end Developer

5. Tester and Quality Assurance Manager

The platform has been developed with AGILE principles which promote not only sustainable programming but also a solid development framework to follow. All the project lifecycle and future maintenance and/or upgrades will follow these principles. The agile program development comprises a family of project management methodologies characterized by the division of all primary requirements of a project into subcategories of requirements and deliverables, in order to achieve their planning over a short period. The primary purpose of this methodology is that, at the end of each development cycle named iteration, which usually lasts a few weeks, there is a functional version of the software developed with a minimum number of bugs.

The limited availability of medical staff and the previous experience of the technical team proved to be a stability factor in the development process. Janssen and Van der Voort ${ }^{5}$ recognize how government agencies and semi-public institutions, hospitals and private organizations can take advantage of such management methods ${ }^{7}$ during uncertain times like the COVID-19 crisis.

Another important feature characterizing the AGILE methodology is the frequent communication between team members through the daily and weekly meetings named scrum to communicate the progress and the encountered problems. The results of these sessions are then communicated to the client, who will thus be informed of all the aspects of software development, such as a flexible and interactive method leading to a reduction in development risks and execution time.

The main methodology derived from the AGILE principle that has been used by the Project Manager 
is SCRUM, which is characterized by the following principles:

- It is iterative - specific iterations and functions of the project are progressively delivered before the project is completed;

- It is time-based - closely tracks deadlines and quantifies by fixed iterates all the requirements divided into subcategories;

- Open to the beneficiary - the client is involved by regularly being presented the stage of the project, and he can decide on specific changes/ adjustments during the evolution of the project;

- As part of the proposed solution for this project, the allocated team ensured the successful implementation of the project by organizing regular planning meetings as well as work review and retrospective meetings. In order to facilitate communication, weekly meetings were also scheduled to facilitate the exchange of information and to remove possible obstacles.

During the process of implementing the platform, the technical team has continuously maintained the communication process through the following means of communication: telephone, e-mail, video conferencing, meetings taking place at the beneficiary's premises, workshops and revision sessions.

\section{DESIGN AND DEVELOPMENT}

Modern web technologies have been used in order to allow the operability of the SANINFO software platform before the smooth registration of several types of users: platform administrator, specialist, and researcher. The technologies underlying the development of the SANINFO platform are known as progressive web apps (PWA) type, as they consist of a combination of web APIs, technologies and design concepts that create a native application experience in a mobile browser. PWA applications are stored on servers, can be accessed through URLs and are indexed by search engines.

The following requirements need to be met so that SANINFO is framed in a progressive web application:

1. Progressive - to work for any user regardless of the chosen browser as it is built based on the basic principle of progressive improvement;

2. Independent connectivity - to work offline or in low-quality networks;

3. Fresh - always updated;

4. Secure - served by HTTPS (active SSL);

5. Installable - allow users to „keep” the app they find most useful on the Linkable home screen;
6. Linkable - can be easily shared via URL while not requiring a complex installation.

The following technologies have been selected for the development of the SANINFO application:

1. Angular 6 - Angular is a platform that makes it easy to build applications on the web. Angular combines declarative templates, addiction injection and integrated best practices to address development challenges ${ }^{7}$.

2. Bootstrap - web framework based on predefined HTML and css elements, suitable for mobile platforms as well ${ }^{8}$.

3. Node.js and Underscore framework - serverside javascript runtime environment used by Nkenyereye and Jang ${ }^{9}$ in the development of a healthcare Hub

4. Java and the Spring Framework - serves as the back-end system to interact with the database managed on a MongoDB instance.

The expertise of the project team followed a qualitative analysis of the available framework technologies for the achievement of graphical interfaces until deciding that Angular should be used for the web application developed. This framework is an open-source technology that enables the development of dynamic load interfaces based on TypeScript language.

The main advantage of using this technology is given by the minimum consumption of resources on the end user's device, regardless of the environment from which it accesses the platform (PC, laptop, mobile phone, tablet). It is considered an unusual web interface because the application makes requests to SANINFO application servers only for content modified during its use.

These dynamic communication protocols have, also, been found in other ReactJs, VueJs, JQuery frameworks considered by the developers as alternative solutions.

\section{THE MAIN FUNCTIONS OF THE PLATFORM}

The development of the functional structure of the SANINFO software platform started from the following main objectives:

1. Informing (with the concentration on prevention) the public about various medical fields, especially those specific to cluster members: Medical Engineering, Nutrition, General Medicine, ICT, Dentistry; 
2. Providing maximum visibility for published medical studies and scientific works;

3. Developing a technical tool to contribute to the digitalization of the medical industry;

4. Making it accessible 24/7 regardless of the visitor location;

5. Easing the management of the site as well as the information update.

\section{DESIGNING THE VISUAL ELEMENTS}

In order to build a visual identity of the SANINFO online application, the initial requirements stated that the design to be modern, relevant for the healthcare system, professional, trustable, focused on providing relevant information, depending on the sections displayed. Thus, the contrast between the letters (writing) and the background was expected to be large enough for quick viewing of the content. The fonts used were intended to ensure the readability of text regardless of the browser or user platform.

The initial graphic design proposals were intended to create unitary and recognizable visual concepts. At the same time, the style for displaying the information was planned to be uniform on all pages by category (title, headers, lists, text).

In order to avoid increasing long training and support sessions on the HIS platform, novel approaches are needed for proper integration of the system 6. During the design phase of the application, the team took advantage of the context eLearning functions that explain users the path to be taken in order to reach the desired outcome.

Based on the study carried out on existing medical platforms at the national and international level, the following color palette was selected:

CODE: 7ec357 - Light green

CODE: 0687aa - Dark blue

CODE: 688aee - Blue to purple

CODE: e15554 - Red

CODE: 59c8d5 - Light blue

The premises underlying the decision on the selected colors (logo, graphics, icons, banners) were those that blue is the best health field, and red is specific to the domain of the Management Entity of the cluster (Smurd Association Galati), respectively emergencies. The color palette used throughout the application was intended to ensure multi-platform compatibility, consistent with the visual identity of each thematic route or the diversity of the medical specializations. The design has been optimized for low resolutions (mobile), medium and large resolutions (desktop version).

All images used in the development of the platform comply with applicable copyright-free regulations and optimized for viewing on different resolutions.

A unitary style was used for all pages that follow the visual identity of SANINFO and the agreed structure during the design stage. Adding a new page can be performed quickly, being the same as other basic actions in terms of writing style, layout, filling of blank spaces, the contrast between background and text color will be large enough to ensure the best readability. The structure of the information is made one in a tree-like manner, with categories and subcategories easily accessible and easy for users to navigate.

During the planning phase of the SANINFO development project, various types of Graphic Forms have been established, so that the page structure is reflected in the Site-map. A total of 25 Graphic Forms have been made and revised in the feedback collection sessions with the project team to ensure the compliant functionality of all SANINFO platform requirements.

\section{ESTABLISHING THE HARDWARE ARCHITECTURE AND HOSTING ENVIRONMENT REQUIREMENTS}

SANINFO platform has been designed to function as a private cloud hosting system, maintaining the focus of the development team on four main factors: (1) performance, (2) redundancy, (3) scalability and (4) security. The redundancy of the hardware system established for hosting the SANINFO application translates into a continuous availability of all services and functionalities, the equipment operating in parallel, ensuring all operations in optimal parameters, even if the hardware support fails. This redundant architecture also ensures that the allocated equipment is not overloaded, having the system automatically distributing processes in a balanced way.

From a data security point of view, backup safety rescue solutions have been included, ensuring the rapid recovery of data and the operation of the platform in case of severe damage or even natural disasters. As for maintaining the confidentiality of user data, an additional protected server is being used for storage, configured with redundant firewall devices, as well as firewall software solutions providing extra protection. Confidential data are not accessible through the platform, 
but only through the internal management server while following all GDPR regulations.

The hardware system used to host the SANINFO application is a server-based web application. In order to allow fast scalability in a future update, the platform was developed and deployed using modern clusterization and virtualization environments. Logical and physical architectures are designed to obtain the lowest response times, thus avoiding latency from the platform on the data processing side.

The results show that it is much more efficient to use local hardware infrastructure. Thus, the SANINFO software platform, once developed, will involve some minimum technical requirements, as well as the existence of a central server at the company's headquarters.

The hardware resource needed to secure and configure a server system was provided by one of the cluster members, the maintenance costs being fully insured for one year after the launching of the platform.

Thus, a server has been built, and it provides the following configuration for hosting the innovative SANINFO system:

$\begin{array}{ll}\text { - } & \text { CPU Processor: } 10 \text {-Core Intel }{ }^{\circledR} \mathrm{Xeon}^{\circledR} 4114 \\ & \text { 2.2GHz-3.00GHz } \\ \text { - } & \text { RAM: } 32 \mathrm{~GB}(1 \times 32 \mathrm{~GB}) 2400 \mathrm{MHz} \\ \text { - } & \text { Disk Space: } 2 \text { x } 240 \mathrm{~GB} \text { Read intensive SSD }\end{array}$

The current database architecture is built on top of MongoDB and has access to all of the features and extensions this has to provide. We are also making heavy use of the map-reduce inherent functionality which MongoDB has to offer, in order to speed up queries and make all hardware resources more efficient. All of the implementation tweaks on top of the turnkey database solution (MongoDB) have been validated during the experimental testing stage. It has been concluded that the same objective could have been achieved by using a relational database management system (RDBMS), i.e. any SQL database, but scaling and speed would have been impacted in the long run, as we increase the amount of data. The reliability of the database structure is a vital point of these applications. It is necessary to be validated as an architecture given new and emerging technologies in the market, promising to simplify the interaction with undefined data structures considerably.

Together with a high-performance internet connection, equipment with platform logic must provide system response times to all targeted users while all platform features will be accessible simultaneously for a large number of connected users. Data storage equipment is configured with state-of-the-art software which ensures the management of a large volume of documents. This service is made available to users as an additional functionality compared to an ideal collaborative platform.

\section{BACKUP AND RESTORATION SYSTEM}

In contrast with a traditional medical office, the SANINFO platform is designed to be operational 24 hours a day, seven days a week, with the possibility of simultaneously supporting a minimum of 10.000 different users. From a data security perspective, the hardware system provides a backup and restore module that runs automatically, with a certain periodicity to back up the site. It is thus safe to restore the site correctly and entirely on the basis of backups, but there is also the possibility of recovering the information without completely restoring the computer system. In the case that a page is deleted, the system marks it as deleted, but its content is retained in history. Content version management will be easily accomplished from the administration interface.

Along with the hardware system (server), installation kits and installation manual will be made available, following specific procedures step by step, in which the running order of installation programs, SQL comman$\mathrm{ds}$, configuration and any other information is needed to restore the database. The system will be configured to save information automatically and periodically based on a schedule set with the system administrator.

In order to ensure the integrity of the platform, the following security plans have been developed: (1) data backup plan and procedures for user-ordered data for saving various external storage destinations/supports, (2) disaster data restoration plan and procedures; (2) ensuring the continuity of the operation of the disaster system (redundancy plan); (3) restoring the entire system as well as the saved data on a backup system.

These security plans have been developed following these steps:

Daily backups are performed on an external server from another location to ensure disaster redundancy;

Backup is done in full, including system + databases;

Restoration is enabled via Rsync with Jetback-up (www.jetbackup.com)

In the event of a disaster, Jetback-up has an integrated Disaster Recovery function which can be activated very quickly and in a relatively short amount of time. Is useful due to this functionality 


\section{DEPLOYING THE APPLICATION}

The web pages design meets all the compatibility and accessibility requirements, following the W3C (World Wide Web Consortium) specifications and the Web Accessibility Initiative (WAI) recommendations, supported at the international standards in the field of web accessibility. For developing the app, all Internet browsers (Internet Explorer, Microsoft Edge, Mozilla Firefox, Google Chrome, Opera, Safari) with their latest versions (not older than two years) have been considered in order to display the content and the implemented functionalities correctly.

The following functions have been established as possibilities for further development of the SANINFO platform:

1. Advanced filtering development for Articles and classification by authors and keywords (tags) in articles;

2. Platform connection with other existing medical applications at the national and international level (e.g. academic databases);

3. Extension of the platform to other regions and medical cluster formations, consortia;

4. Additional options for researchers: add collaborators, ongoing projects and current activities;

5. Additional options for Specialist users: possibility to pick up requests and manage an appointment or scheduling calendar;

6. Development of native mobile apps for Android and IoS.

The computer system has been implemented in such a way as to protect the following vulnerabilities:

- Cross-site scripting (XSS) and reflected crosssite scripting (RXSS);

- Content spoofing;

- Predictable resource location SQL injection;

- Insufficient authentication;

- Directory indexing;

- HTTP response splitting;

\section{TESTING AND VALIDATION OF THE PLATFORM}

All testing activities of the software solution were considered empirical investigation, carried out to provide interested parties with information on the quality of the product or service being tested, taking into account the operational context in which the platform would be used.
Several testing software was used for providing an objective and independent view of the developing product, thus allowing the beneficiary to understand and evaluate the risks associated with the implementation of the software product.

Testing techniques include, but are not limited to, the process of running the program or application to identify software flaws or errors. Software testing can also be defined as a process of validation and verification that a software/application/product (1) meets the technical requirements that guided its design and implementation and (2) runs and behaves as expected.

The primary purpose of the testing process is to identify software errors and to isolate them in order to fix or correct the defects that caused these errors. The design of large software applications, developed within a team is done by moving directly to the implementation of the program and follows well-established steps.

The development process of the SANINFO software application consists of the following steps: specification of requirements, analysis, design, implementation, testing and maintenance.

During the planning stage, the requirements for all elements of the system, both hardware and software, were determined. Thus, the requirements for the SANINFO software application were analyzed by the tester together with the beneficiary.

The testing of the specifications was carried out by the following methods of static analysis: inspections, scrolling and technical analysis.

The main operating requirements that have been tracked in the IT platform testing process were to make sure that the functionality and integration perform properly. Also, the usability for the end-user and the performance on different devices are in the accepted parameters.

The following main functions have been tested:

1. Publication of scientific articles and grouping them;

2. The interaction of author-readers is achieved by posting comments and approving them in advance by the platform administrator;

3. The dynamic online chat function is imperative with a preset, displayed program;

4. Interactivity with doctors via an online form, possibility of sending questions/messages;

5. Interactive map with the listing of doctors/experts;

6. Individual pages describing the professional activity of doctors and applying different filters; 
7. In order to facilitate access to information, patients can submit consultation requests and view the doctors' availability;

8. Calendar of medical events in the South-East Region.

The testing of the SANINFO platform was carried out in the environment where the online resource was accessed by the beneficiaries, the technical development team, as well as by piloting with a sample of 10 users, consisting of members of the cluster having various specializations: Ph.D. students, doctors, entrepreneurs.

During the project testing phase, globally recognized online tools were used in order to verify the accuracy of all design and functionality elements as well as the internal procedures for testing performance. All testing and verification processes for final solutions were performed on the following display standards (views):

a) Desktop Mode, on the following standards:

- Resolutions Full HD: 1960X1080, 1366X768, 1024x600, and the most popular web browsers: Chrome, Mozilla, Safari, Internet Explorer - latest version at the date of this study;

- Compliance with the approved mockups (graphic layouts) as final, by comparing the original design with the implemented one: logo, fonts, item arrangement, spacing and alignment, sizing, colors, the existence of all elements (images, position sections).

- Checking all content pages and the initial brief (design specifications: hover effects on buttons, parallax, hover menu, arrows, drop down, pointers);

- Verification of functionalities;

b) Responsive Mode, on Android and iOS and mobile/tablet resolutions: 320-480, 768-1024, the following benchmarks were taken in ScreenFly application: Apple Ipad, Samsung S3-S9, Asus Nexus 7, iPhone 5-xs):

- Compliance with existing mockups, comparing the original design with the implemented one: logo, fonts, arranging elements, spacing and alignment, sizing, colors, the existence of all elements: images and content sections

- Checking all content pages and the original brief, following design specifications such as hover effects on buttons, parallax, hover menu, arrows, drop down, pointers;
- Verification of functionalities starting the initial planning;

The methods used in the SANINFO platform testing process aimed at obtaining the following results:

1. Testing and validation of access to the web interface: saninfo.ro as well as login data (credentials) on the Administration Panel and user types: Researchers and Specialists;

2. Testing and validating web browsing for all primary and secondary pages (Sitemap) for the Desktop and Responsive (mobile, tablet) modes, as well as compatibility with the three most popular browsers: Chrome, Mozilla, Safari.

\section{INTEGRATION OF ALL REQUIREMENTS RESULTING FROM THE SYSTEM}

Following the testing and verification processes of the platform's functionalities, bug-fixing sessions as well as optimization of the user experience were carried out for optimizing items such as User Experience (UX) and User Interface (UI). The term bug fixing means any request to repair an error, shortcoming, mistakes, failure or malfunction of the live system that produces an incorrect or unexpected result, or causes it to behave in unintentional ways. A number of bugs or operating errors have been identified and resolved so that the resulting computer system is fully functional.

Prior to the live launch of the SANINFO app, a number of specific tests were performed:

- Testing under loading conditions, requests and continuing

- Security testing

- Easy use Testing

- Indexing elements in search engines

- Link testing.

After the live implementation of the saninfo.ro platform on 10.31.2019, the following response time procedures have been defined according to the situations that may affect the functionality of the computer system

- a critical dysfunctionality: response time 1 hour, remediation time 2 hours;

- a major dysfunctionality: response time 2 hours, remediation time 4 hours;

- a normal malfunction: response time 2 hours, repair time 24 hours. 


\section{CONCLUSIONS AND FUTURE UPDATES}

The updating and maintenance of the SANINFO system will be carried out by the Management Entity of the cluster, through the administration panel based on the access levels created, whenever appropriate, except for technical assistance. To this end, the online platform has an interface in place that provides easy management and use by designated individuals. Based on open source technologies, the online platform will also allow for the subsequent addition of new pages and features, which have a flexible structure and form of administration. The next feature to be implemented is the Multi-Language functionality in order to increase the platform accessibility for international users.

In this state, a number of 78 articles are published on the platform, 20 specialists are registered with individual accounts, and 51 researcher accounts are created with different roles (medics, Ph.D. students, researchers, chemists, engineers, lecturers), and eight medical events have been listed.

Summarizing all of the above specifications, we can conclude that the success of the platform is technically influenced by the achievement and maintenance of the following goals:

1. Design a comprehensive., real-time platform for collaboration and interaction;

2. The constant interaction between healthcare professionals and users;

3. Accessibility and intuitiveness of the platform;

4. Providing up to date and relevant content on the platform, in real time;

The most achievable result of the project is the development of the SANINFO platform, freely available on the market. Currently, the Management Entity does not have the intention of making an income by using the platform following the closure of the project but is considering the subscription integration after a more comprehensive community is built with the help of this platform.
They were implementing the principles of quality assurance and management within the SANINFO project, in particular the process-based approach, in order to meet the requirements regarding the quality of the software implementation process by the project team members.

It is essential to mention that in the context of COVID-19 local entrepreneurs have started a series of endeavors to sid the local hospital ecosystem. The SANINFO platform played a crucial role in finding stakeholders interested in the development of mechanical ventilators and medical face masks $\&$ visors that were donated.

It is vital to maintain an up-to-date version of the platform with relevant content and engage the medical community in the management of specific updates and/or content creations and curation. The limited availability of the highly qualified personnel in the medical arena represents an actual challenge, but overcoming it will have a significant impact on the local communities. Digital health 11 is an emerging market that currently is not regulated, and it can lead to numerous research projects considering the data that can be gathered in the online environment. More research is required to understand the necessary technologies, and how they can be integrated into the patient communication pipelines.

Compliance with ethics requirements: The authors declare no conflict of interest regarding this article. The authors declare that all the procedures and experiments of this study respect the ethical standards in the Helsinki Declaration of 1975, as revised in 2008(5), as well as the national law. Informed consent was obtained from all the patients included in the study.

Acknowledgement: This work was supported by a grant of the Romanian National Authority for Scientific Research and Innovation, CNCS/CCCDI - UEFISCDI, project number PN-III-P2-2.1-CLS-2017-0045, within PNCDI III. Project name: Developing an Innovative Health Information System - SANINFOM, with applications in the Romanian language for the Innovative Cluster for Health „Dunarea de Jos”. 
Viorica BADEA et al.

\section{References}

1. Rangraz Jeddi, F., Nabovati, E., Bigham, R., \& Khajouei, R. (2019) Usability evaluation of a comprehensive national health information system: relationship of quality components to users' characteristics. International Journal of Medical Informatics, 104026. doi:10.1016/j.ijmedinf.2019.104026.

2. Faujdar, D. S., Sahay, S., Singh, T., Kaur, M., \& Kumar, R. (2020) Field testing of a digital health information system for primary health care: A quasi-experimental study from India. International Journal of Medical Informatics, 141, 104235. doi:10.1016/j. ijmedinf.2020.104235

3. Martikainen, S., Kaipio, J., \& Lääveri, T. (2020). End-user participation in health information systems (HIS) development: Physicians' and nurses' experiences. International Journal of Medical Informatics, 137, 104117. doi:10.1016/j.jimedinf.2020.104117.

4. J. Hess, D. Randall, V. Pipek, V. Wulf, Involving users in the wildparticipatory product development in and with online communities, Int. J. Hum. Stud. 71 (5) (2013) 570-589. [27]

5. Janssen, M., \& van der Voort, H. (2020). Agile and adaptive governance in crisis response: Lessons from the COVID-19 pandemic. International Journal of Information Management, 102180. doi:10.1016/j.jijfomgt.2020.102180.

6. Rudd, K. E., Puttkammer, N., Antilla, J., Richards, J., Heffron, M., Tolentino, H., ... Santas, X. M. (2019). Building workforce capa- city for effective use of health information systems: Evaluation of a blended eLearning course in Namibia and Tanzania. International Journal of Medical Informatics. doi:10.1016/j.ijmedinf.2019.08.005.

7. Tung, C.-W., Wang, C.-C., \& Wang, S.-S. (2018). Mechanisminformed read-across assessment of skin sensitizers based on SkinSensDB. Regulatory Toxicology and Pharmacology, 94 276-282. doi:10.1016/j.yrtph.2018.02.014.

8. Verber, D., Novak, D., Borovič, M., Dugonik, J., \& Flisar, D. (2020) EQUIDOPA: A responsive web application for the levodopa equivalent dose calculator. Computer Methods and Programs in $\mathrm{Bi}-$ omedicine, 105633. doi:10.1016/j.cmpb.2020.105633.

9. Nkenyereye, L., \& Jang, J.-W. (2016). Performance Evaluation of Server-side JavaScript for Healthcare Hub Server in Remote Healthcare Monitoring System. Procedia Computer Science, 98, 382-387. doi:10.1016/j.procs.2016.09.058.

10. Mahajan, S., Lu, Y., Spatz, E. S., Nasir, K., \& Krumholz, H. M. (2020). Trends and Predictors of Use of Digital Health Technology in the United States. The American Journal of Medicine. doi:10.1016/j.amjmed.2020.06.033.

11. Lowery, C. (2020). What Is Digital Health and What Do I Need to Know About It? Obstetrics and Gynecology Clinics of North America, 47(2), 215-225. doi:10.1016/j.ogc.2020.02.011. 